\title{
Outsourcing Customer Service: Applying The Value Chain As A Method To Improve Service At Call Centers
}

Barbara Mihm, University of Wisconsin-Stevens Point

\begin{abstract}
The practice of outsourcing customer support for the information technology sector has grown substantially in the last decade. U.S. companies operating in the low margin personal computer industry maintain this practice is necessary to increase profitability and remain competitive. Firms that make decisions to outsource in lower cost countries need to ensure that customers are satisfied with the level of service provided and minimize negative experiences and irate customers. Because the work of call centers is often outsourced to far flung corners of the world on a lowest bid contract, with an emphasis on transaction costs, levels of service can be uneven. This research examines data from customer satisfaction surveys on personal computers regarding technical support from the manufacturers Dell, Hewlett-Packard, and Apple, which was gathered by Consumer Reports in March, 2006. By comparing the overall satisfaction levels to the companies' outsourcing policies, some correlations are drawn. The research concludes with specific recommendations on how to provide higher levels of service with fewer variations through the use of metrics that measure quantifiable results.
\end{abstract}

Keywords: computer industry, information technology, outsourcing, offshoring, customer satisfaction, call centers.

\section{INTRODUCTION}

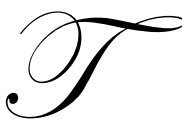

he practice of outsourcing customer support for the information technology sector has grown substantially in the last decade. In fact, many U.S. companies operating in the low margin personal computer industry maintain this practice is necessary to increase profitability and remain competitive. As the practice has continued to grow, so has public outcry surrounding the issue of customer service. Firms that make decisions to outsource in lower cost countries need to ensure that customers are satisfied with the level of service provided and minimize negative experiences and irate customers. Lower costs mean little if the firm loses customers because of poor service. Because the work of call centers is often outsourced to far flung corners of the world on a lowest bid contract, with an emphasis on transaction costs, levels of service can be uneven. This research examines data from customer satisfaction surveys on personal computers regarding technical support from the manufacturers Dell, Hewlett-Packard, and Apple, which was gathered by Consumer Reports in March, 2006. By comparing the overall satisfaction levels to the companies' outsourcing policies, some correlations are drawn. The value chain is used as a theoretical model, drawing a distinction between cost saving per transaction and customer satisfaction. Outsourcing relationships can be viewed as opportunities to move beyond transactional cost approaches to relationships which foster responsive strategies to build customer satisfaction. If this occurs, the call center's importance in the value chain is greatly increased. The research concludes with specific recommendations on how to provide higher levels of service with fewer variations through the use of metrics that measure quantifiable results.

\section{OFFSHORE OUTSOURCING}

Before examining the call center situations it helps to understand Business Process Outsourcing (BPO) under which call centers are grouped. Basically, this term describes situations when a firm outsources its back office functions to a third party through the use of information technology, typically to a lower cost country. This 
makes the practice both offshoring and outsourcing. Outsourcing has been defined as hiring the knowledge, expertise, and human power of a vendor to do tasks a firm no longer wishes to do (Alder, 2003). Offshore outsourcing often includes call centers for customer service but can also include accounting, human resource, research and development, and engineering functions. The industry is growing very fast. In 2000, 125 top U.S. companies used this process. In 2003, 285 out of the top 500 U.S. companies were using BPO (Kripalani, et all 2004). Accurate numbers are difficult to come by since the U.S. does not track the number of jobs leaving the country, and offshore outsourcing numbers are estimated (Hilsenrath, 2004). However, a prediction from an expert in the area states the number of dollars outsourced will grow from 110 billion in 2002 to 173 billion in 2007 (Traylor, 2003). There are estimates that the trend will continue, with Fortune 100 companies cutting employee numbers in half by 2008 as a result of BPO (Traylor).

While many U.S. companies maintain that offshore outsourcing is necessary to remain cost competitive, others see the trend as a threat to the U.S. economy, particularly in terms of job losses. However, a bigger question remains-is the trend really providing customers with the level of service they expect? When the calculation that it costs between 5 and 100 times more to win a new customer over keeping an existing customer (De Bonis et all, 2004) is applied, going with the lowest cost service provider does not always make sense if that provider turns existing customers away because of poor service.

The explosive growth of BPO is directly related to attempts at cost savings. And countries with an abundance of highly educated English speaking workers that have substantially lower costs for operations and wages, like India, are logical locations for BPO. Additionally, there are a number of very experienced U.S firms offshoring call centers and help desks such as General Electric, IBM, and Accenture. These firms have been successful in setting up their own call centers in India to compete with the large experienced Indian firms like Wipro and Infosys, which provide support services for many U.S. companies. Also, there are a number of U.S. service provider firms that operate call centers all over the world, with the top five being Convergys, EDS, TeleTech Holdings, West, and Sitel (Jastrow, 2003).

This competitive picture makes the outsourcing decision highly cost sensitive (Traylor, 2003). Simonson (2002) terms the solution outsourcers provide a 'transaction engine', which occurs when "The inputs, outputs and working rules are so well-defined that there is no doubt as to how the work will be completed" (p.2). While in some situations outsourcing may be viewed as simply shifting transactions to a provider with the lowest cost, many customer service transactions require a high level of interaction on the part of the person handling the phone call. In these cases, understanding the entire process becomes an important factor in meeting the customer's expectations for service. However, the pressure that U.S. corporations put on outsourcers to lower their cost, creates an atmosphere in which the quality of service is continuously diminishing. In fact, a recent article in Business Week notes that many Indian outsourcers are turning down call center contracts in favor of higher pay work (Kripalani, 2006).

The cost saving benefits can be substantial beginning with labor. While labor savings might run up to 80 percent less than U.S. costs, the real savings after management costs, training, technology, and the cost of running a remote call center in a foreign country, results in typical savings of 40-60 percent (Simonson, 2002). Wired magazine recently calculated the hourly cost of a typical call center in Kansas City, Missouri at $\$ 12.47$ for equipment, labor, and profit as compared with $\$ 4.12$ per hour in Mumbai, India. The hourly wage difference was $\$ 10$ per hour in the U.S. to $\$ 1.50$ per hour in India (Pink, 2004).

Other reasons companies move to offshore outsourcing include changes in technology. Information Technology allows for databases with customer information to be accessed virtually anywhere with fiber-optic cable and satellite technology. The cheap cost associated with the transmission of information is a primary driver of BPO (Friedman, 2005).

Consumer demands for service at all times also is a factor which requires many companies to provide 24/7 service for their customers. For example, contracting with a call center in India makes this possible because of the 11 hour time difference. In many developing countries, employees are willing to work on weekends for the same wage as on weekdays, contributing to the cost savings factor. 
Additionally, U.S. companies operating in the global economy are under relentless pressure to remain competitive and efficient from all sides. Potential customers look for the best value at the lowest price. Wall Street demands results. Shareholders want to see profits and cost-saving measures undertaken by the companies they invest in. With BPO, companies can free up capital to use in other areas, making better use of their resources.

While these factors are valid, many companies have not taken time to calculate the cost for the loss of customers when customer service is less than what is expected. Many times decisions are made based on the lower cost offered in a long-term transaction based contract. When the contract focuses on transactions, such as payment per call answered there is often a lack of concrete criteria established to determine what measure will be used to ensure customers are satisfied. And when a firm decides that customer support provided by call centers is no longer a part of its core business, it is reasonable to question whether farming these calls out to a low cost provider will cause service to be lower and increase customer dissatisfaction.

\section{OUTSOURCING AND THE VALUE CHAIN}

Call centers and customer contact centers are typical business functions that are outsourced through BPO because many firms do not consider service as a part of core business functions. However, there is considerable evidence that customer satisfaction and customer retention are closely linked to a business's' profits and long term survival. Businesses can calculate the cost of obtaining new customers and the lifetime values of existing customers. Continual recruitment of new customers is much more costly than keeping existing ones. Customer lifetime value (CLV) attempts to calculate the value of a customer over time, predicting future spending behaviors. The key to customer value over time is servicing the customer today to ensure her business in the future. Firms that place emphasis on customer lifetime value and customer relationship management (CRM), a selective business which attempts to pinpoint and manage the most valuable customers are interested in long term relationships with customers. CRM is a business strategy that requires commitments from all levels of management as well as multiple functional areas. "CRM requires a customer-centric business philosophy and culture to support effective marketing, sales, and service processes." (Thompson, 2001p.1) Both CLV and CRM have caused a shift in thinking from transactions to long term relationships (Zeithaml, 2000 Kern and Wilcock, 2000; Paladino et all, 2002). Thus, many strategic initiatives focus both on reducing transaction costs while attempting to maintain appropriate levels of customer service which will result in return customers.

Software vendors have been quick to build products around the concept of CRM. There has been an explosion of vendors selling customer relationship management software which helps firms make better use of the data and activities that occur between trading partners. These so called "CRM software solutions" allow firms to gather and warehouse data related to customers enabling them to service customer needs better. Through sophisticated analysis of the data, firms are better able to adjust their behavior and utilize specific strategies in response to the value each customer has to the firm (Boulding, et all 2005). However, while software programs can certainly help firms sort through information about customers true customer relationship management requires a shift to building relationships that increase in value.

A major influence on the concept of evaluating the importance of the various processes both inside the firm and outside the firm is through the value chain. Michael Porter in 1985, was the first to coin the concept of the value chain, which basically breaks the various processes that take place in a firm from start to finish of the product or service, such as production, logistics, marketing, and customer service. By looking at each of these processes and determining how value can be added, firms can better understand their competitive advantage. Porter, along with the development of the value chain concept, has been a leader in recognizing the concept of core competencies and the benefits of outsourcing those areas not considered core competencies that others can handle more efficiently and effectively. By outsourcing, firms can focus on what is essential to their business and what they do best. While vertical integration has been a control strategy for some large firms, many others. particularly in the computer industry, have opted to outsource tasks viewed as non-essential or non-core. If outsourcing is pursued as a costsaving measure offshore outsourcing becomes even more attractive because of labor arbitrage. It is common knowledge that both Dell and Hewlett-Packard have utilized this method for at least the past 8 years. The argument in this research then, is that these firms have failed to correctly identify the true value of customer service. Because 
of a myopic focus on lower transaction costs, Dell and Hewlett-Packard have failed to develop collaborative relationships within the value chain from those they contract with for call center service.

Interestingly, Gartner an IT consulting firm, notes that 60 percent of all outsourcing agreements will result in substantial losses of customers. Gartner also predicts that 80 percent of firms which outsource customer service functions will fail to meet their cost savings targets. Furthermore, Gartner found that many of the predicted costsaving fail to materialize, with the top 15 percent of global companies paying 30 percent less for in-house service that those firms outsourcing their customer service (Pruitt, 2005) While labor arbitrage per transaction may be the initial motivator for offshore outsourcing, it seems that low cost call centers fail to live up to expectations.

Of course, firms that operate in highly competitive environments need to use business strategies which allow them to cut costs and many times these cost cutting measures result in contracts with outsiders to complete tasks that can be done more efficiently by a third party service provider. However, cost cutting may involve risking the satisfaction of the most important key public, a firm's customers. Firms need to be able to look outside themselves through the eyes of the customer. One method of looking outside is to use independent customer surveys conducted by firms such as Consumer Reports.

\section{EXCELLENT SERVICE CAN BE PROVIDED}

One of the biggest mistakes companies make is failing to clearly understand what customers' expectations are from a call center. Undoubtedly, there are a number of nightmare situations common to many of us who have used call centers that are known problems to avoid. These include the experience in dealing with a call center where employees have been unable solve problems and seem to be reading from a script, to complaints of problems with foreign accents and communication problems due to language barriers, to being trapped in a automated loop where a customer never gets to talk to a human being (Kurtz, 2004). But avoiding these problems is not enough to ensure satisfied customers.

Service excellence can be described as "that which the customer perceives as providing the service they require quickly, conveniently and without error, delivered courteously by knowledgeable staff at an acceptable cost" (Jones, 2004, p.2). The key here is that the focus is on what the customer perceives, not what the company thinks the customers want. Firms cannot do a good job of providing service whether it is outsourced or is in-house if they do not regularly ask customers about the service provided and if that service met their expectations. It also means developing clear performance measures and talking corrective actions if measures are not met. Customers want their problems dealt with quickly and efficiently, with as little hassle as possible. In most cases, customers are more concerned about getting their problems resolved quickly and to their satisfaction, than they are about where the call center is located.

Generally, tasks that are fairly routine and repeatable are the easiest to transfer offshore. Tasks that can be transaction engines as mentioned previously, will often work in offshore outsourcing, provided certain conditions are in place. These conditions include a deep relationship between the companies and contracts that are based on customer satisfaction rather than number of calls handled per hour. Tasks that are central to a company's core business should not be outsourced. Oftentimes companies make the mistake of thinking that customer service is not central to their business. Fundamental to the question of outsourcing is being able to see what is important to the customer.

Certainly, there is a balance between what service can be provided and costs. Using a third party can significantly cut costs. But when selecting a vendor firms can do some things to improve the level of service provided. Besides using customer satisfaction as a key metric, companies should make sure the vendor they consider has a significant knowledge of the firm's industry. In other words, if a firm is outsourcing a help desk for computers, the vendor needs to have experience and deep knowledge of the P.C. industry. The people working the technical support center need to understand computer problems and need to be empowered to act beyond a few answers from a script. They need to be real problem solvers. Additionally, contracts need to be set up to build customer 
relationships, penalizing poor results and rewarding good results (Compton, 2004). This is why long-term contracts to the lowest bidder, which do not include satisfaction criteria are a huge mistake.

A McKinsey quarterly article (Harmon et all, 2006) recently cautioned executives on the danger of looking only at financial metrics when measuring performance in customer service. Because service situations are highly variable the consulting firm urges service providers to develop a "best practices" gauge to monitor service in these varied situations. If the computer manufacturers fail to develop long term relationships with call center providers including requirements of best practices that insure customer satisfaction that are standardized for all the call centers, levels of service will continue to be hopelessly uneven.

McKinsey reports that there are three essential principles that should underpin all service measurements (Harmon, et all, 2006). First, firms should use internal comparisons to benchmark levels. By benchmarking internally against clearly defined measures, companies are better able to measure progress. Second, firms need to closely examine financial costs in search of root problems that are causing the expenses. Getting to the bottom of a reoccurring problem could result in the reduction of service calls. While this sounds logical, many outsourcing call centers do not share information with clients. In fact, since many call centers are paid per call there is little to gain by attempting to reduce the number of incoming calls. Third, broad cost measurement information systems need to be used to compare expenses across functional areas. If costs are assigned to departments that have no incentive to operate cross functionally, a mindset of 'its their problem not ours' sets in. If departments fail to work together to solve problems service levels will remain low. Thus, the sharing of information between departments within firms as well as communication between the call center and various functional areas becomes very important.

The company that wants to provide excellent service from an outsourcer needs to be willing to share key information with the outsourcer including "its vision, strategic direction, goals, concerns, as well as how it communicates with customers and suppliers through sales, marketing and customer support. Armed with this information, outsourcers can identify best practices that are most suited for each customer" (Myron, 2003, p.3). The outsourcer then becomes a business partner sharing in a firm's stake with its customer. The outsourcer and the firm become joint problem solvers by analyzing the problems and attempting to figure out why the problems are occurring in the first place, providing the company with valuable data (Compton, 2004). Goolsby (2004) notes that long-term outsourcing relationships only succeed if there is mutual trust built on the proof that that both parties are jointly committed to each other's interests. Today's information systems make this possible, if companies are willing to invest in relationships with outsourcing vendors instead of simply looking at call centers as something removed from the main business.

Forrester Research cautioned companies concerning the problems associated with BPO problems in a recent report. They found "inflexible contracts, difficulty managing vendors, and lack of performance metrics" (BPO News Roundup, 2003) as being key obstacles in improving BPO relationships. The report also highlighted the fact that long-term contracts to the lowest bidder are meaningless if there is little confidence in the service provided.

Kern and Willcocks (2000) investigated information technology outsourcing relationships and found that trust between partners took time to develop and evolved as the terms of the agreement were accomplished. Firms in outsourcing relationships identified adaptation and goal convergence as part of becoming strategically closer. The authors note in their contrast between short-term contractual elements and on-going relational contracts which evolve over time, the later requires strong interpersonal communication between top managers of the firms. Cooperation and commitment between the firms were seen as implicit in the relationships.

Dell, Hewlett-Packard, and Apple are competing against each other in what is considered a very tight profit industry. Much has been written about the fact that declining margins on computers has eroded profits and squeezed the manufacturers into looking for ways to cut costs. Many argue that computers are simply commodity type items with the major differentiation factor being customer service (Carr, 2004). Clearly there is relentless pressure because of intense competition between Dell and Hewlett-Packard, while Apple has been able to stay out of the price war because of its unique operating system, a clear competitive advantage. The price pressure forces the firms to consider using outsourcing to support call centers thereby reducing their costs. There are links between methods 
the manufacturers use for customer tech support and satisfaction levels. By examining the outsourcing practices used and comparing overall satisfaction levels, some preliminary correlations can be drawn. The practice of outsourcing customer support been widely used in the Information Technology industry since the early 1990s (Kern and Wilcock, 2000). However, because customer dissatisfaction levels continue to be high it appears that firms are not giving customer service its true importance in the value chain.

\begin{tabular}{|c|c|c|}
\hline Manufacturer & Desktop Score & Laptop score \\
\hline Apple & 77 & 82 \\
\hline Dell & 55 & 58 \\
\hline H.P. & 50 & 55 \\
\hline
\end{tabular}

Scores are from Consumer Reports March 2006. Surveys were conducted on subscribers in January 2004June 2005. There were approximately 4200 responses for laptops and 6500 for desktops. Questions were asked about manufacturers overall technical support. A high score of 100 means total satisfaction, 80 means very satisfied and 60 is fairly well satisfied. Apple is clearly ahead with satisfaction levels from their P.C. owners being close to 70 percent higher than P.C owners of Dell or H.P.

\section{OUTSOURCING PRACTICES}

Dell sold more machines than all other P.C. manufacturers during the period the survey was conducted and is an experienced player in the offshore outsourcing call center business. However, its experience has not been enough to prevent high levels of customer dissatisfaction with customer support provided by some call centers. Dell has faced major challenges in addressing customer complaints. In 2003, the firm had the dubious distinction of leading the number of customer complaint filings at ConsumerAffairs.com for computer firms. Since that time, problems have escalated and dissatisfaction with Dell service is a common complaint. Part of the reason that service levels are uneven is due to the fact that Dell contracts with about 30 call support center around the globe (Zieger, 2004). In 2005, Dell had a record number of complaints 1,533 to the better Business Bureau more, than double the number in 2004 (Lee, 2006). Because the Dell's model has been to continually lower costs, service and its weight in the value chain has been miscalculated. In 2006, because of the excessive customer complaints, the company was forced to shore up its service in North America by 20 percent, and add an additional call center in India. However, it does not appear that Dell has a critical mass of service technicians in its overseas call centers. Instead, it uses an approach of farming the service out to many different providers, which can mean very different service, depending on the service center the customer is connected with. Because theses firm operate independently, there is little opportunity to share information.

For example, the 24/7 Customer Call Center in Bangalore India, employs 2,500 workers to take and make calls for hundreds of firms. People working there are assigned to small teams representing multi-national firms such as Dell and Microsoft. The young, educated workers take calls as the name implies 24/7, in conditions similar to typical office jobs in the U.S. These jobs can save companies about 80 percent in wages (Friedman, 2005). While savings in labor may be substantial, the service levels can be inconsistent because there is no critical mass of employees connected directly with Dell at the call center. And those workers at the call center in India have a lack of knowledge as to what is going on in the other 29 call centers around the globe.

Dell experienced major problems with one of its technical support call centers in 2003. And the firm found out the hard way that covering the basics was not enough to satisfy its best customers. When it pulled the plug on is corporate customer service call center in India and transferred these most valuable accounts to service centers in the U.S. late in the year, it did so because of the huge number of complaints and threats of business losses due to irate business customers. Dell's customers made their dissatisfaction known loud and clear and Dell responded (Technology Brief, 2003). While Dell brought the corporate business back to the U.S., it continued to operate Indian call centers for non-corporate customers. 
Clearly, as the Dell case shows, since all customers are not created equal, firms will want to take care to make sure those most valuable customers receive the highest level of service possible (Dawson, 2004).

Customer service needs to be part of business outcomes rather than an after thought. But for Dell, with operations in 30 different countries and many different contact centers in each of these countries it is difficult to determine if the same levels of service are being provided, especially if the main driver is cost savings instead of customer satisfaction. Dell should apply the same standards to all of its call center operations no matter which third party is providing the service. However, for Dell to achieve this, a uniform metric needs to be established to measure levels of satisfaction. Then the same metric should be used in each call centers to monitor levels of service. To ensure consistency, Dell needs to apply the same standards that it uses in its U.S. operations, to the offshore call centers.

Hewlett-Packard has been a leader in off-shore outsourcing, and has made extensive use of offshore call centers to cut costs. Hewlett-Packard found through experience that to make sure customers are satisfied, outsourced call center contracts need to be set up to pay per resolution instead of per minute. They found out that upfront investments in training are important. H.P. also found that a good approach to take with a vendor for call centers was to add to call volume at call centers only as customer satisfaction levels were met. The business case at H.P. for offshore outsourcing is driven not only by labor and start-up costs, but by customer satisfaction levels taking future sales and profits into account (Curtland et all, 2004). But the survey numbers from Consumer Reports fail to show that customers are in fact satisfied most recently. Perhaps earlier commitments have been abandoned with the financial pressures H.P. continues to face.

However, H.P. has had some success using an online customer support system which is in-house. By closely monitoring incoming e-mails and using a quick response goal the firm can get a pulse on its own service. Typically, responses to inquiries are answered within 10 minutes according to the head of U.S. customer contact centers in the U.S. for H.P. Interestingly, this quick service has reduced the number of calls to call centers. In 2004 and 2005 while email inquires rose, call center volume decreased. Since it costs 60 percent less to respond to an email over a phone call, Hewlett-Packard has benefited financially from the quick response times (Clark, 2006). Remember, this measurement is from the company's non-outsourced customer service. Again, this shows that uneven levels of service are occurring because of the fact that H.P. uses multiple call centers both in-house and outsourced. Unless the same metrics are applied all over the globe, the levels of service will be unpredictable.

The information on Apple and its outsourcing practices is somewhat limited. The point needs to be made that the sales of Apple are considerably less than the Dell and H.P. Apple personal computers make up less than 3 percent of the P.C. business (Weber, 2005). Because of the difference in numbers sold, there will be fewer complaints and less publicity. Another key factor is that one of the major problems customers need help with is machines infected with spyware and viruses which are designed to attack Windows machines. The operating systems in Apple have been relatively safe from this problem. Recent surveys found that about 70 percent of all computer problems are the result of spyware (Miller, 2005).

There is evidence of a key difference in the Apple approach to opening call centers in other countries. In March of 2005 an Apple representative was quoted in an update to the press picked up by News.com. When asked about plan to open a Bangalore call center the spokesperson said:

Apple has gained millions of new customers in the past year, and we are building a call center in India to help meet our growing service and support needs"....The company emphasized that it isn't downsizing any U.S. jobs, pointing to its continued growth both in the U.S. and other markets. "Our call centers in Austin and Sacramento also continue to grow," the Apple spokesperson said in the news briefing. Recognizing the importance of quality service, the company promised continued high levels of support for both its computers and iPods...."This call center will be managed and staffed by Apple employees with the same award-winning service for which Apple is known around the world" (Why Apple's Closing, 2006). 
Apple has since changed its plan and has scrapped its plans to open the call center in Bangalore, claiming that the cost savings to do appear to be as substantial as originally thought. Thus, it seems that Apple is applying a much higher value to customer service in its value chain than Dell. Apple is practicing a think before it leaps mentality to outsourcing approach.

\section{CONCLUSIONS AND RECOMMENDATIONS}

The call center is often considered an afterthought with customer service not given the importance it warrants in the value chain. The sharing of information between call centers and the computer manufacturers could actually lead to better products. However, if there is not a relationship between business partners there is little incentive to share information. In some cases, outsourcing might not be the best way to handle service. Firms need to clearly articulate the correct value of service. As pointed out many firms overestimate potential savings gained outsourcing. In summary, there are some guidelines that can be gleaned from the literature that a firm considering outsourcing can use in the decision process. There are six main areas to consider.

First, a company needs to be clear on what its core business is and who its most important customers are. Firms need to accurately reflect the value of the call centers in their value chains. Oftentimes, companies make the mistake of thinking that customer service is not central to its business, when in fact, the service the company provides is its competitive advantage.

Second, companies need to survey their customers and find out what their expectations are in the process of a call to a call center. Without a clear idea of what customers' expectations are it is impossible to satisfy them. With this information clearly detailed, call centers and their clients need to establish specific metrics for satisfaction. Internal benchmarks need to be tracked to determine if satisfaction is improving. Surveying customers could include finding a way to give customers a choice. Some customers might be willing to pay to have a service problem solved in the U.S. rather than dealing with an offshore provider.

Third, companies need to do their homework and investigate the options for outsourcing. Outsourcers that have deep knowledge of a company's industry should be given top consideration and firms need to be sure that savings are really possible. As Gartner Consulting noted, outsourcing contracts often do not meet anticipated cost savings and can actually end up costing firms more than it would to run the centers in-house (Pruitt, 2005).

Fourth, contracts should be written with payment linked to customer satisfaction not only on the number of calls. Goolsby (2004) refers to outsourcing relationships that move beyond a buyer/seller situation driven only by cost to a 'Business Transformational Outsourcing' relationship in which a 'we' attitude, based on mutual trust and commitment, open communication multiple levels, with collaborative solutions transforming how business is done. Business outcomes drive the partnerships and when customer satisfaction is given a priority as a business outcome, call centers are more likely to provide high levels of service. However, this only occurs when a deep relationship had been built to support the sharing of information.

Fifth, firms need to regard information as king in the call center area. Continual information sharing and open communication are essential if good service is to be provided. The better the outsourcing party understands a company's business, the greater its ability to service customers. This only happens when a real partnership is developed and continuing communication is a priority. Sophisticated software programs which monitor calls into call centers process can be used as trouble-shooting tools. Since the software can track the number of problems occurring, managers are better able to see patterns of problems as they develop (Ortolani, 2004). And information systems that link functions areas of firms with information gleaned from call centers can be very useful.

Sixth, investigate the options technology can provide. One of the biggest improvements in the technical service area has been through online help desks. Because the foreignness of the experience is minimized this type of service often works better for high tech industries. Additionally, much progress has been made in automated speech recognition technology which can cut down on wait times for fairly common problems. 
In conclusion, BPO will continue to be a major issue for U.S. firms, particularly in the area of customer support call centers because of evolving technologies. However, many firms are now beginning to recognize that anticipated cost saving do not materialize. Whether firms decide to keep service in-house or outsource, firms need to carefully address the value of customer service in the value chain.

\section{ACKNOWLEDGEMENTS}

The author acknowledges the support of the University Personnel Development Committee.

\section{REFERENCES}

1. $\quad$ Adler, P. (2003). Making the HR outsourcing Decision. MIT Management Review.45 (1)53-61.

2. Boulding, W, Staelin, R., Ehert, M \& Johnson W. (2005) A customer relationship management roadmap: What is know, potential pitfalls, and where to go. Journal of Marketing.69 155-166.

3. BPO News Roundup (2003). Customer Relationship Management. 7(11)3. 11/2003.

4. $\quad$ Carr, N. (2004). Does It Matter? Boston: Harvard Business School Press.

5. Clark, H. (2006). Customer service goes to hell. Forbes.com April 5,2006. www.wired.com/news/technolgy/internet.

6. Computers from den to living room. (2006). Consumer Report, March, 2006. www.ConsumerReports.org (23-28)

7. Compton, J. (2004). How to choose the right contact center outsourcer. Customer Relationship Management. 8(2) 2. 2/2004.

8. Curtland, C., Cargille, B., Ellis, S. \& Goodwin, R. (2004). Is offshoring really cheaper? Call Center Magazine.17(1)48. 1/2004.

9. Dawson, K. What we learn from Dell's experience. Call Center Magazine. 17 (2) 6.2/2004.

10. De Bonis, N., Balinski, E. Allen, P. (2004). Value-Based Marketing for Bottom-Line Success. New York: McGraw-Hill.

11. Drucker, J. \& Brown, K. (2004). Press 1 for Dehli, 2 for Dallas; Latest wrinkle in jobs fight: Letting customers choose where their work is done. Wall Street Journal. B.1 3/9/2004.

12. Friedman, T. (2005). The World is Flat. New York: Farrar, Straus \& Giroux.

13. Flynn, L. (2003). Companies sending work abroad are learning cultural sensitivity -to their American customers. The New York Times. Section C. 4.

14. Goolsby, K. (2004). Required reading on the realities of business transformational outsourcing: Success principles for BTO relationships. Outsourcing Best Practices.com. 4/2004.

15. Grant, P. (2004). 1-800-Useless. Wall Street Journal. 7/26/2004.R.5.

16. Harmon, E. Hensel, S. \& Lukes, T. (2006). Measuring performance in services. McKinsey Quarterly. March, 2006 (1).

17. Hilsenrath, J. (2004) Behind outsourcing debate: Surprisingly few hard numbers. The Wall Street Journal. 4/12/04, A.1

18. Jastrow, D. (2003). What you need to know about call center outsourcing. Customer Relationship Management. 7(11)6-10. 11/2003.

19. Johnson, D. (2001). Is this a real person? Management Communication Quarterly 14 (4) 659-665.

20. Jones, C. ( 2004). Developing a scorecard for service quality. Management Services. 48 (4)1-11 .

21. Kern, T. and Wilcock, L. (2000). Exploring information technology outsourcing relationships: theory and practice. Journal of Strategic Information Systems. 9 (2000) 321-350.

22. Kripalani, M. (2006). Call centers That's so 2004. Business Week August 7, 2006.

23. Kripalani, M., Hamm, Spencer, E. \& Reinhart, A.(2004). Scrambling to stem India's onslaught. Business Week. 81-82. 1/26/2004.

24. Kurtz, R. (2004). The problem: Angry customers. Languages issues. Phone static. Maybe outsourcing the help desk wasn't such a great idea after all. Inc. 26(7) 48-50.7/2004.

25. Lee, L. (2006). It's Dell vs. the Dell Way. Business Week. March 6, 2006.

26. Miller, M. (2005). Tech support: Still a ways to go. PCMAG.COM. www.pcmag.com

27. Myron, D. (2003). BPO gets a CRM History lesson. Customer Relationship Management. 7(11)2. 11/2003. 
28. Ortolani, A. (2004). Call-monitoring industry is booming. The Wall Street Journal 11/29/04 A.11.

29. Palandino, M Bates, H. \& Da Silveira (2002). Using a customer-focused approach to improve quality across the value chain: the case of Sidecar. Total Quality Management 13(5) 671-683.

30. Pink, D. (2004). The new face of the silicon age. Wired. 94-138. 2/2004.

31. Porter, M. (1985). Competitive Advantage :Creating and Sustaining Superior Performance. New York. Free Press

32. Pruitt, S. (2005). Gartner: Customer service outsourcing often fails. IDG New Service. March 04, 2005.

33. Simonson, E. (2002). Part 2 What's driving the growth of BPO? The emergence of transaction engines. BPO Outsourcing Journal. 12/2002.

34. Thompson, B. (2001). What is CRM? The Customer Relationship Primer, CRMguru.com January, 2001.

35. Traylor, P. (2003). Outsourcing. CFO 19(15) 24-26.

36. Technology Brief, (2003). Technology Brief--Dell Inc. Corporate support calls. The Wall Street Journal. 11/24/2003.A.1

37. Weber, R. ( 2005). Can't help loving that Mac of mine. Journal of Financial Professionals. November, 2005 (38).

38. Why Apple's Closing of Bangalore Call Center Makes Sense. (2006). The Biz of Coding. www.thebizofcoding.com/2006/06/why apples closing of bangalor.html.

39. Zieger, A. (2004). Talking back: Dell discusses its growing pains. ConsumerAffairs.com Available online: http://www.consumeraffairs.com. [11/19/2004].

\section{NOTES}

